\title{
IDENTIFICAÇÃO DE FALHAS TRANSCORRENTES EM SEÇÕES SÍSMICAS
}

\author{
PEDRO VITOR ZALÁN*
}

\begin{abstract}
The main criteria used in identifying strike-slip faults in seismic sections are (1) flower structures (positive or negative); (2) change from normal to reverse fault along strike, (3) upthrown block switching side along strike, (4) several kinds of changes along strike, (5) reversal of or change in fault throw with depth, (6) abrupt changes in the thickness of seismic facies or stratigraphic intervals across the fault, (7) abrupt changes in seismic facies across the fault, (8) abrupt changes in structures and intensities and/or styles of deformation across the fault, and (9) complex geometries of the fault plane. The usefulness of these criteria lie in the fact that a very restricted number of seismic sections (two or three, sometimes even a single one), largely spaced and crossing the fault zone at great angles, is enough to determine the existence of wrench tectonism in a target area, Such recognition has important economic implications because it increases the variety of potential traps that can possibly exist along the fault trend.
\end{abstract}

INTRODUÇÃo A tectônica transcorrente tem sido extensivamente revista pela literatura geológica mundial durante os últimos 30 anos. As estruturas associadas (dobras e falhas en échelon), suas relações espaciais e temporais com a zona de falha principal, suas origens (deduzidas a partir de experimentos de laboratório), a distribuição mundial de zonas de cisalhamento importantes e seu potencial petrolífero estão detalhadamente discutidos nos clássicos trabalhos de Moody \& Hill (1956), Wilson (1965), Tchalenko (1970), Harland (1971), Lowell (1972), Harding (1973), Wilcox et al. (1973), Harding (1974) e Harding \& Lowell (1979). A relação entre tectonismo transcorrente e sedimentação começou a ser bem entendida com os trabalhos de Crowell (1974a, 1974b, 1975), sendo sumarizada por Reading (1980) e ilustrada em diversos artigos presentes na publicação especial n. 04 da International Association of Sedimentologists (Ballance \& Reading 1980). Os conceitos básicos de tectonismo transcorrente, por serem bem conhecidos, não serão discutidos em detalhe neste trabalho.

A tectônica transcorrente teve sua importância renovada nos últimos anos devido ao grande volume de dados sísmicos obtidos pela indústria de petróleo nas bacias sedimentares do mundo inteiro. Os geocientistas de petróleo começa* ram a reconhecer que o papel desempenhado por falhas transcorrentes na evolução geológica de bacias sedimentares era muito maior que o previamente suspeitado. Isso foi particularmente revolucionário nas bacias cratônicas da América do Norte, Mar do Norte e Brasil; e nas bacias de margem passiva. Nas margens ativas de placas, esta impartância já havia sido reconhecida anteriormente (por exemplo, Califórnia e Indonésia). Várias falhas de alto ângulo, normalmente interpretadas como normais ou reversas, foram reinterpretadas como falhas transcorrentes. Verificou-se que certos dobramentos tinham sido causados por transpressão em vez de simples compressão. A origem de várias bacias passou a ser atribuída a esforços transtensionais** (movimentos transcorrentes com componentes extensionais) em vez de simplesmente extensionais. Compreendeu-se que a maioria das bacias sedimentares sofre, durante sua evolução, um ou mais eventos de tectonismo transcorrente, quando então falhas preexistentes são reativadas por deslocamentos laterais e seu preenchimento sedimentar sofre inversão estrutural (positiva por transpressão ou negativa por transtensão). Recentes esquemas de classificação global de bacias sedimentares dão grande importância a eventos tectônicos transcorrentes na evolução das mesmas (Kingston et al. 1983).

Conseqüentemente, o reconhecimento do caráter transcorrente de zonas de falha em seções sísmicas tornou-se cada vez mais importante. Tal reconhecimento traz importantes implicações econômicas por ele aumentar a variedade de trapas potenciais de hidrocarbonetos que podem existir ao longo da đireção da falha. Diversos conceitos novos sur giram e permitem, hoje em dia, reconhecer fathas de deslocamento lateral em seções sísmicas (seçōes verticais).

Critérios clássicos de geologia de campo não podem ser usados para identificar falhas transcorrentes em seções sísmicas. A maioria das bacias sedimentares que sofreram reativações tectônicas de caráter transcorrente apresenta deslocamentos laterais de blocos de pequena escala. Na maioria dos casos é muito difícil discernir, por mapas de atributos de subsuperfície, rejeitos horizontais de elementos estruturais ou estratigráficos ao longo das falhas. Observou-se, entretanto, que a maioria das falhas, ao possuírem uma componente de movimentação horizontal, apresenta respostas sísmicas características, que se repetem de bacia para bacia. Um determinado número de critérios sísmicos foi estabelecido e eles podem ser seguramente usados para se estabelecer o caráter transcorrente de uma zona de falha. 0 objetivo deste trabalho é discorrer brevemente sobre tais critérios e ilustrá-los com exemplos de seções sísmicas de bacias brasileiras. Os intérpretes sísmicos atuais devem estar familiarizados com tais conceitos, já que a ocorrência de falhas transcorrentes em bacias sedimentares está muito mais para uma regra do que para uma exceção.

CRITÉRIOS SIŚMICOS OS critérios usados na identificação de falhas transcorrentes em seções sísmicas são aqui listados, discutidos e ilustrados. Pode-se antecipar que, entre esses critérios, apenas um deles (estrutura-em-flor) pode

\footnotetext{
* Petrobrás/Depex. Av. Chile, 65, $13 .^{\circ}$ andar, CEP 20031, Rio de Janeiro, RJ, Brasil

* Deve-se ressaltar, entretanto, que a adaptação mais correta do termo transtensional seria transtracional, já que, em português, a palavra tra* cional é usada no sentido de esforços extensionais, como tradução do termo inglês tensional
} 
ser usado como indicador definitivo de transcorrência. Os outros devem ser usados coletivamente, ou associados a outras características em planta da zona de falha, para se determinar o caráter transcorrente da mesma. Quando dois ou mais desses critérios são observados ao longo da direção de uma zona de falha, tem-se uma boa indicação de que se está provavelmente lidando com uma falha transcorrente.

Estruturas-em-flor A assinatura sísmica mais característica de uma falha transcorrente, em seção vertical, é deno. minada estrutura-em-flor (Harding \& Lowell 1979, J.F. Dewey, comunicação verbal, 1983). Na literatura inglesa utilizam-se os termos flower structure, piercement structure (Kingma 1958) e palm tree structure (D'Onfro \& Glagola 1983). Estruturas-em-flor são zonas de falha em forma de cunha, que se abrem de baixo para cima, situadas acima de uma falha principal subvertical profunda, e que normalmente afeta o embasamento. Esta zona em cunha é formada por várias falhas subsidiárias que, em perfil, podem apresentar a geometria de falhas normais, reversas e de empurrão. Todas elas convergem para baixo em direção à falha principal enquanto que, para cima, se abrem em leque (Figs. 1A e 1B). Emmons (1968) ilustrou esplendidamente a geração de estruturas-em-flor ao longo de rupturas transcorrentes em experimentos de laboratório utilizando caixas de areia. De acordo com este autor, o padrão geométrico da zona de falha sendo confinado na base e alargado no topo foi consis* tentemente obtido nos vários experimentos envolvendo deslocamentos laterais. Sylvester \& Smith (1976) forneceram a primeira descrição detalhada da geometria de uma estrutura-em-flor em campo, e também discutiram sua origem. Harding \& Lowell (1979) documentaram pioneiramente uma estrutura-em-flor em seção sísmica. Harding (1983) reconheceu dois tipos de estruturas-em-flor: positivas e negativas.

Estruturas-em-flor positivas são definidas como estruturas antiformais lineares, delimitadas e deslocadas por falhas reversas que convergem em profundidade para uma falha subvertical principal (Fig. 1A). Em seções verticais (seções sísmicas), tais feições aparecem como um anticlinal, cujo arco superior é muito maior que o arco inferior, situado acima de estratos não dobrados e cortado por várias falhas predominantemente reversas e convergentes em profundidade (Fig. 2). Deve-se ressaltar, entretanto, que a característica principal da estrutura-em-flor positiva é o predomínio marcante de falhas reversas na região em cunha, e não necessariamente o anticlinal. De uma maneira geral, a região em cunha encontra-se estruturalmente elevada em relação às áreas adjacentes a ela devido à presença de várias falhas reversas, seja sob a forma de um anticlinal ou sob qualquer outra forma (horsts, blocos soerguidos, etc.) (Fig. 3).

Estruturas-em-flor negativas são definidas como estruturas sinformais lineares, delimitadas e deslocadas por falhas normais que convergem em profundidade para uma falha subvertical principal (Fig. 1B). Em seções verticais (seções sísmicas), tais feições aparecem como uma área em cunha abatida, relativamente a suas margens, seja sob a forma de um sinclinal ou sob outras formas (grábens, blocos abatidos, etc.). A característica principal de uma estrutura-em-flor negativa é o predominio marcante de falhas normais na região em cunha, que fazem com que ela seja abatida. Exemplos de tais estruturas podem ser encontrados em Harding (1983) e D'Onfro \& Glagola (1983).

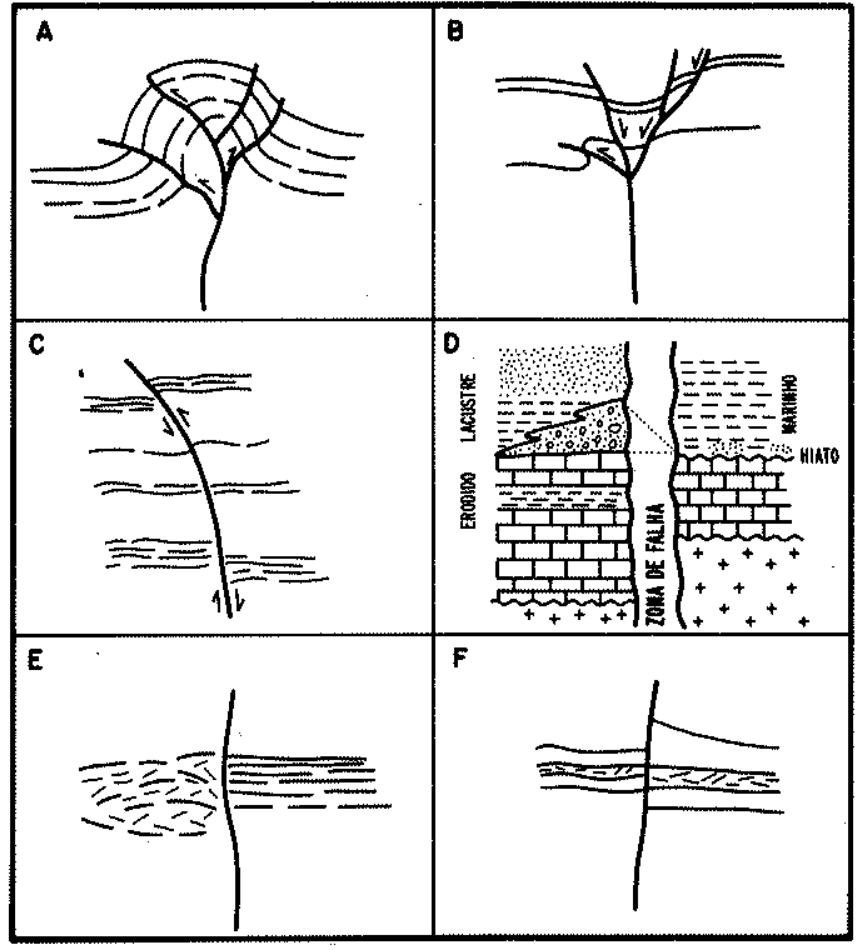

Figura 1 - Estruturas caracteristicas associadas a falhas transcorrentes (vide discussão no texto): A. estrutura-em-flor positiva; B. estrutura-em-flor negativa; C. inversão do rejeito da falha com a profundidade; D. correlaçóes estratigráficas complexas através da falha; E. mudanças laterais abruptas de fácies sismicas, e F. mudancas laterais abruptas de espessura de determinados intervalos

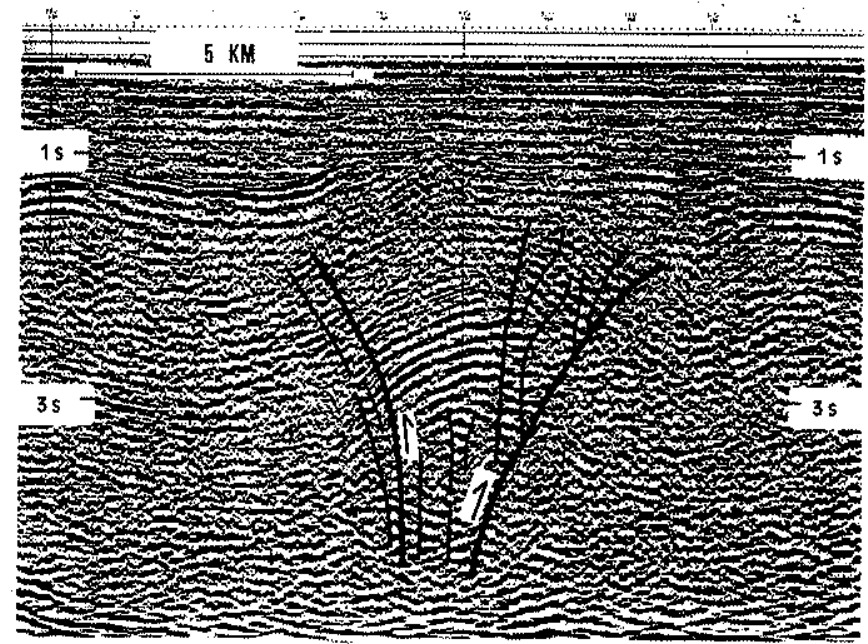

Figura 2 - Estrutura-em-flor positiva afetando sedimentos Albo-Aptianos na plataforma continental do Ceará. Notar formato triangular do anticlinal e convergência das falhas em profundidade. Esta estrutura é denominada Alinhamento Transversal e representa a extensão maritima do Lineamento de Sobral. Seção em tempo migrada 


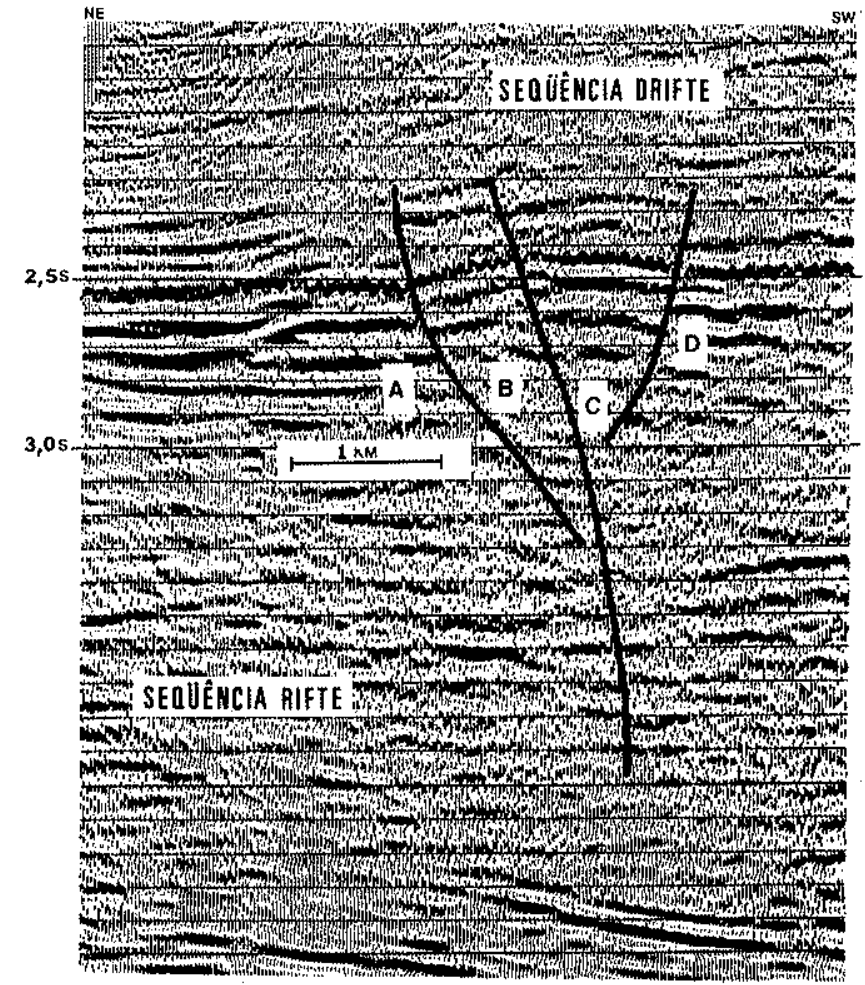

Figura 3 - Estrutura-em-flor positiva afetando sedimentos do Cretáceo da Bacia de Piaui-Camocim. Notar que a regiäo da cunha está soerguida em relação às margens. $A$ fácies sismica da fatia $B$ é ligeiramente diferente (menor intensidade) das fácies sismicas das regiões $\mathbf{A}, \mathbf{C} e \mathbf{D}$ (refletores mais fortes). Tal fato pode ser devido a movimentos laterais, deslocando para o plano desta seção uma fácies mais proximal ou distal (fácies da fatia $\mathbf{B}$ em relação à fácies das fatias $\mathrm{A}, \mathrm{C}$ e D). Seção em tempo migrada

Estruturas-em-flor positivas estão associadas à transcorrência convergente, sendo causadas por esforços transpressionais (movimentos transcorrentes com componentes compressionais). Tal fato foi bem documentado por Lowell (1972) em suas figuras 8 e 9. Estruturas-em-flor negativas caracterizam transcorrência divergente, sendo causadas por esforços transtensionais (vide experimento de Harding 1974, em sua figura 5).

Estruturas-em-flor aparecem geralmente como uma série de estruturas transicionais entre os dois extremos descritos acima (positivas e negativas). Elas raramente são constituídas apenas por falhas reversas ou apenas por falhas normais. Comumente, os dois tipos de falhas estão presentes na região em cunha (Fig. 4). A predominância de falhas reversas ou de falhas normais indicará o ambiente transpressional ou transtensional, respectivamente, de formação dessas estruturas.

As regiōes em cunha dessas estruturas não são também necessariamente simétricas. Estruturas-em-flor apresentando desenvolvimento parcial das regíces em cunha, sob a forma de meia-taças, meia-cunhas ou triângulos retângulos, são comuns (Fig. 5).

Freqüentemente, por motivos diversos, não ocorre o desenvolvimento pleno de uma estrutura-em-flor. Neste caso, sutis indicações de convergência de falhas em profundidade (Fig. 6) ou diminuição de arcos de dobras sobre falhas mais profundas (Fig. 7) podem constituir bons motivos para se desconfiar de movimentaçōes laterais ao longo da zona de falha em questão.

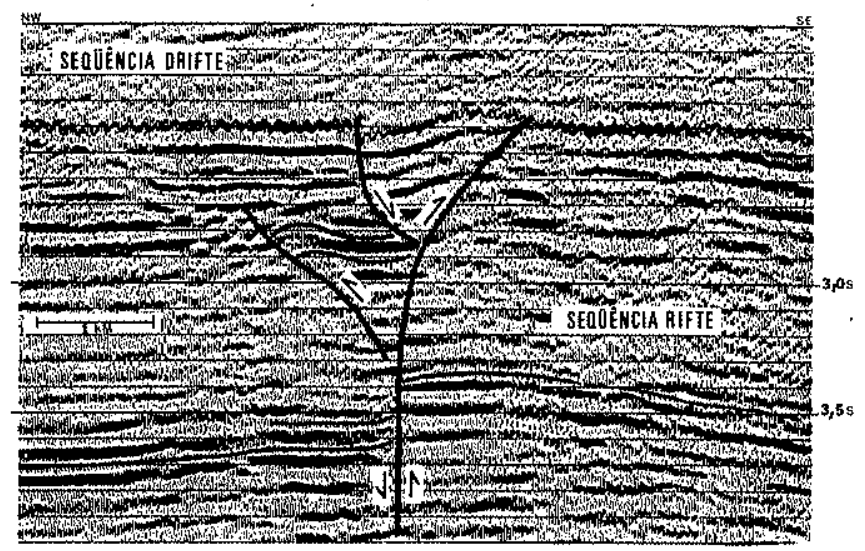

Figura 4 - Estrutura-em-flor composta por duas falhas re. versas e uma normal. Sistema Cretáceo da Bacia de PiauiCamocim. Seção em tempo migrada

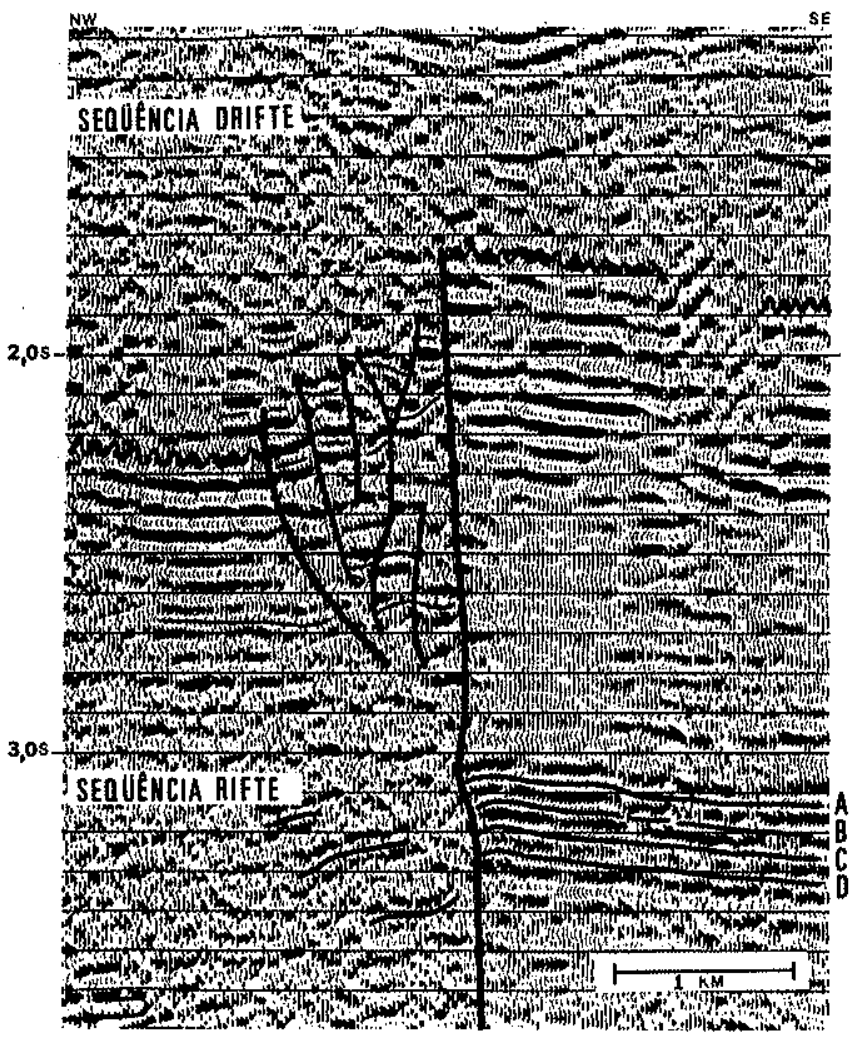

Figura 5 - Meia estrutura-em-flor representada pelo desenvolvimento de uma meia região em cunha em apenas um dos lados da falha transcorrente. Notar a complexidade es. trutural da região em cunha. Observar também, em profundidade, o desaparecimento abrupto dos fortes refletores $\mathbf{A}$, B, C e D do outro lado da falha (justaposição de fácies sismicas diferentes por movimentos laterais). Sistema Cretáceo da Bacia de Piaui-Camocim. Seção em tempo migrada 


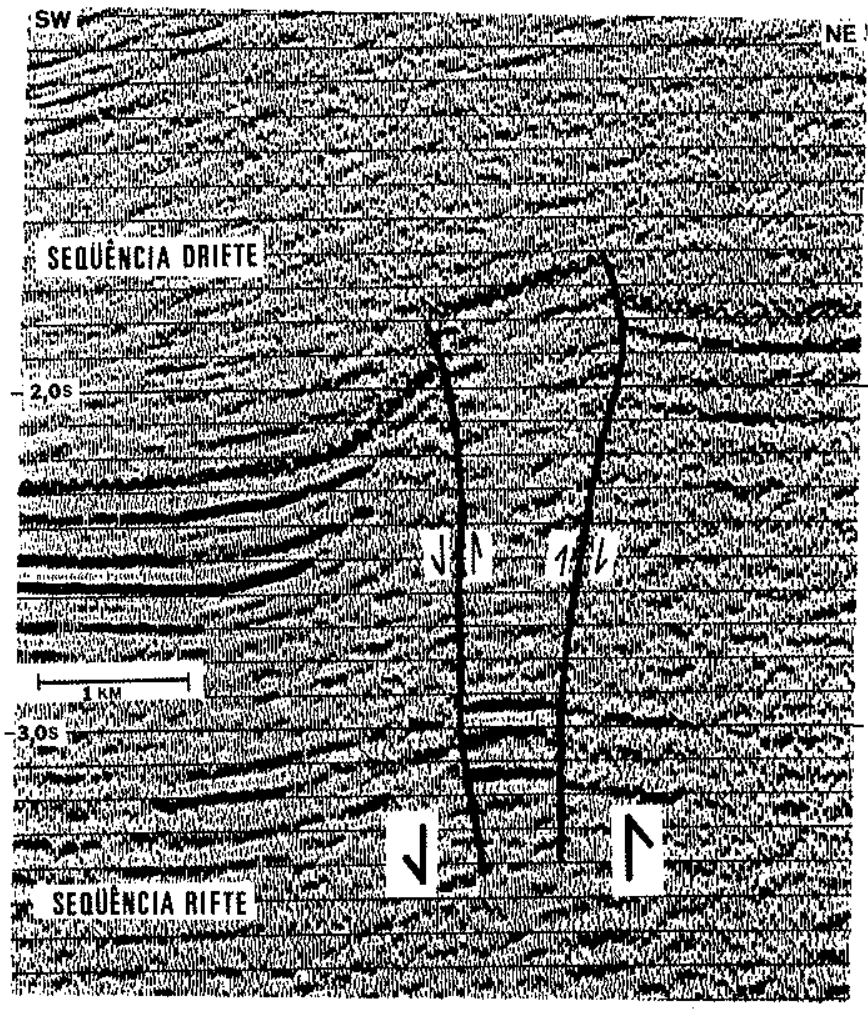

Figura $6-O$ caráter transcorrente desta zona de falha é sugerido pelo acunhamento em profundidade de duas grandes falhas subverticais. Notar que além do possivel rejeito lateral há também um rejeito vertical. Sistema Cretáceo da Bacia de Piaut-Camocim. Seção em tempo migrada

O motivo pelo qual estruturas-em-flor desenvolvem geometria em cunha não está ainda bem estabelecido. Possivelmente, ela representa a diminuição gradual do confinamento deformativo existente entre dois blocos que se movem lateralmente, de baixo para cima. $\mathbf{E}$ como se houvesse uma expansão gradativa, de baixo para cima, da zona de defor. mação. No caso de estruturas-em-flor positivas, o que ocorre é uma verdadeira expulsão seguida de transbordamento dos sedimentos situados entre dois blocos convergentes. Bacias sedimentares inteiras podem ser soerguidas, expulsas de suas cavidades crustais devido à redução de volume das mesmas pela convergência lateral de blocos do embasamento: $\grave{A}$ medida que elas são soerguidas acima das ombreiras do embasamento, o preenchimento sedimentar tende a transbordar e acavalar o embasamento pelas mais complexas estruturas geologicas (dobras, falhas reversas, falhas de empurrão, nappes de charriage). Tal relação ficou bem demonstrada nos trabalhos de campo de Sylvester \& Smith (1976). Este é o fenômeno que se repete, em menor escala, em cada estrutura-em-flor positiva. Estruturas-em-flor negativas representam exatamente o oposto, ou seja, abatimento devido à criação de volume extra entre blocos divergentes.

Estruturas-em-flor desenvolvem-se próximo à superfície terrestre ou a superfícies de contato entre camadas com propriedades reológicas bem diferentes. Por exemplo, na Bacia de Piauí-Camocim a maioria das estruturas-em-flor desenvolve-se no topo da Sequência Rifte (camadas rúpteis), próximo à discordância que a separa da Seqüência Drifte (camadas dúcteis) (Zálan 1984). No Mar do Norte, o desenvolvimento se dá nos sedimentos situados logo abaixo de espessa camada de sal (Glennie \& Boegner 1981). A camada rúptil apresenta a deformação bem impressa, enquanto a camada dúctil, geralmente situada acima, se deforma por fluxo plástico. A deformação das camadas dúcteis dificilmente aparece em 'seções sísmicas, podendo, assim, gerar erros interpretativos quanto à idade do tectonismo transcorrente.

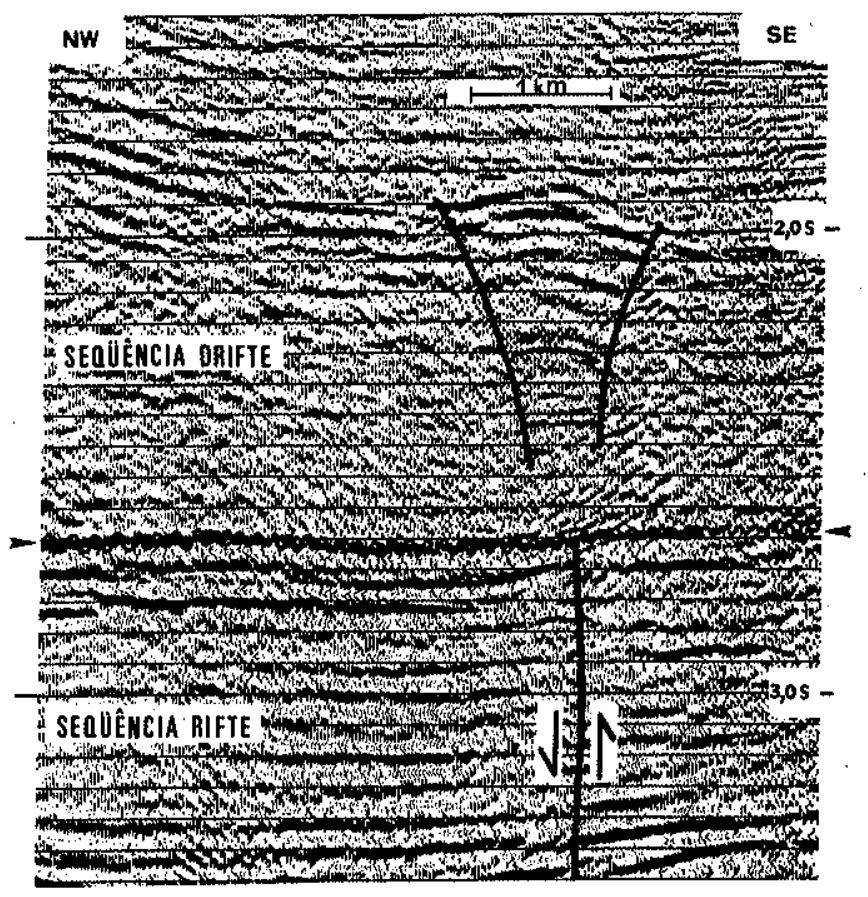

Figura 7 - $O$ acunhamento de uma seção dobrada exatamente acima de uma grande falha subvertical sugere reativação transcorrente de pequena monta associada a esta falha. Sistema Cretáceo da Bacia de Piaui-Camocim. Seção em tempo migrada

Nem todas as falhas transcorrentes apresentam estruturas-em-flor em seções verticais, nem são elas desenvolvidas ao longo de toda a extensão da falha. Elas podem desenvolver-se localmente, enquanto nos outros segmentos as falhas terăo a aparência de simples falhas normais ou reversas (em seções verticais), ou apresentarão outras características de falhas transcorrentes (descritas a seguir).

No estágio atual dos conhecimentos, o reconhecimento de uma estrutura-em-flor é um critério seguro para se afirmar que a zona de falha em questão possui uma componente de deslocamento horizontal, seja ela original ou criada por reativação. Entretanto, é muito importante que sempre se constate que a região em cunha converge em profundidade para uma zona de falha subvertical. Muitas outras estruturas se assemelham a estruturas-em-flor e são resultantes de regimes tectônicos completamente diferentes de transcorrência (falhas lístricas com falhas antitéticas associadas, diapirismo, cinturōes de dobramento, tectônica vertical de blocos, etc.). Na maioria das vezes, essas outras estruturas não estão ligadas em profundidade a zonas de falhas verticais. Neste sentido, o artigo de Harding (1985) é de grande utilidade pois aponta todos os cuidados necessários à correta identificação de estruturas-em-flor e ajuda a manter a integridade destas como indicadores seguros de falhas transcorrentes. 
O Efeito do Golfinho Este efeito foi pela primeira vez descrito por Crowell \& Sylvester (1979, apud Graham et al. 1984) e refere-se ao intenso sobe-e-desce experimentado pelos blocos conforme se deslocam ao longo da falha transcorrente. Emmons (1968) observou que as superfícies das falhas transcorrentes obtidas em seus experimentos eram irregularmente onduladas (tanto na horizontal como na vertical). Conforme os dois blocos crustais se movem horizontalmente ao longo desta superfície de ruptura ondulada, movimentos ascendentes e descendentes afetarão irregularmente cada bloco crustal. Como conseqüência direta deste fenômeno, quatro outros critérios sísmicos surgem:

- A falha muda de caráter (de normal para reversa, e viceversa) ao longo de sua direção (Glennie \& Boegner 1984). O bloco alto pode estar consistentemente do mesmo lado. Neste caso, o que ocorre é apenas mudança na direção de mergulho do plano de falha (Fig. 8A).

- A falha não muda de caráter (sempre normal, ou sempre reversa) ao longo de sua direção. O bloco alto, entretanto, mudará de lado freqüentemente. Neste caso, ocorrem mudanças na direção de mergulho do plano de falha e inversão no movimento relativo dos blocos (Fig. 8B).

- Mudanças gerais ao longo da direção da falha. A falha pode mudar de reversa para normal, e vice-versa; o bloco alto pode mudar freqüentemente de lado, assim como a direção e o ângulo de mergulho do plano de falha podem variar intensamente (Fig. $8 \mathrm{C}$ ). Tal padrão irregular da geometria de uma plano de falha transcorrente foi bem exemplificado por Fagerland (1983, Fig. 3).

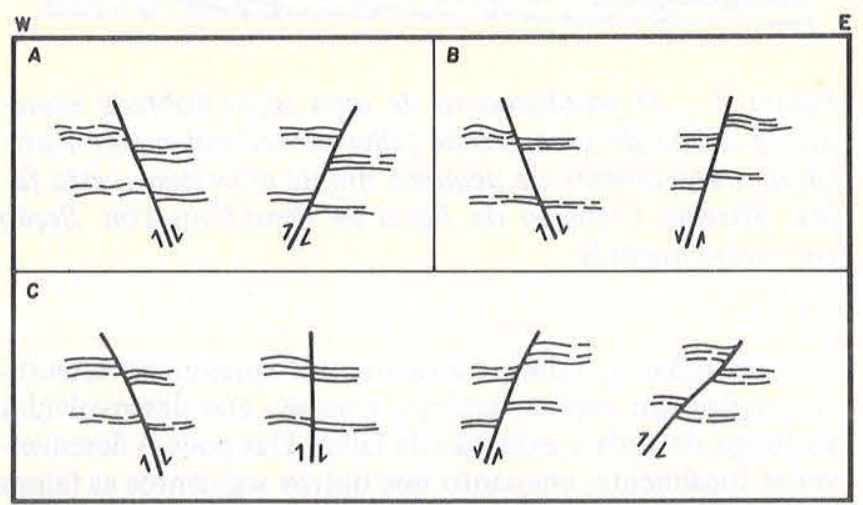

Figura 8 - Cortes transversais esquemáticos de falhas transcorrentes com direção norte-sul, ilustrando comportamentos diversos devido ao efeito do golfinho: A. falha muda de normal para reversa e o bloco alto continua do mesmo lado; B. falha não muda de caráter (sempre normal) e o bloco al to muda de lado; e C. geometria altamente irregular. Falha muda de normal para reversa, e vice-versa. $O$ bloco alto muda de lado constantemente, assim como a direção e o ângulo de mergulho do traço do plano de falha

- Reversão do rejeito aparente da falha com a profundidade (Bodenhausen \& Ott 1981, Glennie \& Boegner 1981, D’Onfro \& Glagola 1983). É muito comum, em uma falha transcorrente, a magnitude do rejeito aparente (visto em uma seção sísmica) variar com a profundidade e até mesmo se inverter para cima ou para baixo (Figs. 1C, 9 e 10). Tal fato pode ser explicado pelo efeito do golfinho ou pela reativação transcorrente de falhas mais antigas, ativas em outros eventos tectônicos, e com rejeitos diferenciais ao longo da seção estratigráfica. A figura 11 mostra um belo exemplo de uma falha da fase rifte de evolução da Bacia da Foz do Amazonas e que continuou agindo como falha normal até o final do Eoceno, quando então foi reativada como falha transcorrente dextral. Aguiar et al. (1986) mapearam esta falha e identificaram dobras en échelon, deslocamentos laterais e reversão de rejeito em seção sísmica (tal como na Fig. 11) ao longo dela.

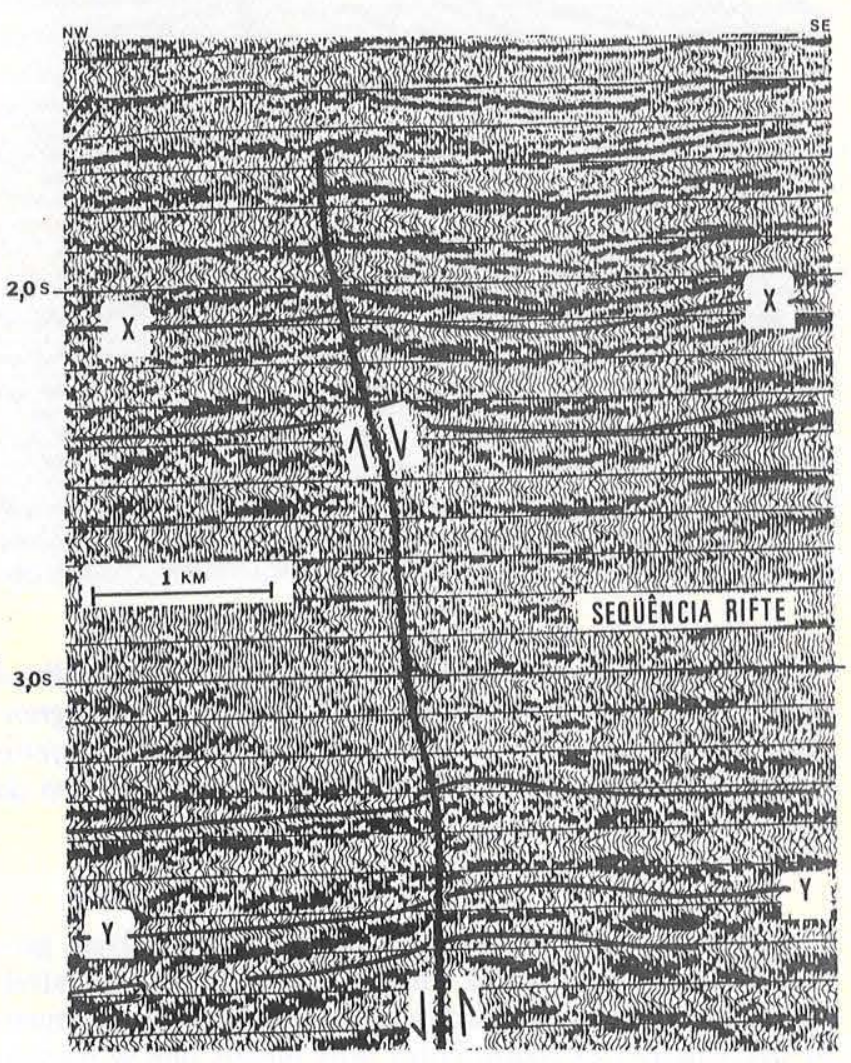

Figura 9 - Seção em tempo migrada mostrando exemplo de falha com reversão no rejeito aparente com a profundidade (utilizar como referência dobras de arrasto nos refletores $\mathbf{X}$ e Y). Sistema Cretáceo da Bacia de Piaui-Camocim

Correlações่ Estratigráficas/Estruturais através da FaIha $\mathrm{O}$ movimento lateral de blocos ao longo de uma falha transcorrente coloca lado a lado fácies sedimentares, litológicas, estruturas e domínios estruturais diferentes. Como conseqüência direta disto, três outros critérios sísmicos surgem.

- Mudanças abruptas na espessura de um determinado intervalo estratigráfico ou fácies sísmica através da falha (Glennie \& Boegner 1981, D’Onfro \& Glagola 1983). A movimentação lateral da falha transcorrente pode justapor partes distais (mais delgadas) e partes proximais (mais espessas) de uma mesma fácies sedimentar. Em uma seção sísmica, tal fenômeno será representado pela ocorrência lado a lado da mesma fácies sísmica, com espessuras bem diferentes (Figs. 1F e 12).

- Mudanças abruptas de fácies sísmicas através da falha. Quando a movimentação lateral é muito grande, fácies sedimentares diferentes podem ser justapostas ao longo da fa- 
lha. Em seçoes sísmicas, tal fato será representado pela ocorrência de fácies sísmicas completamente diferentes, lado a lado, separadas pela falha (Figs. 1E, 3 e 5 )

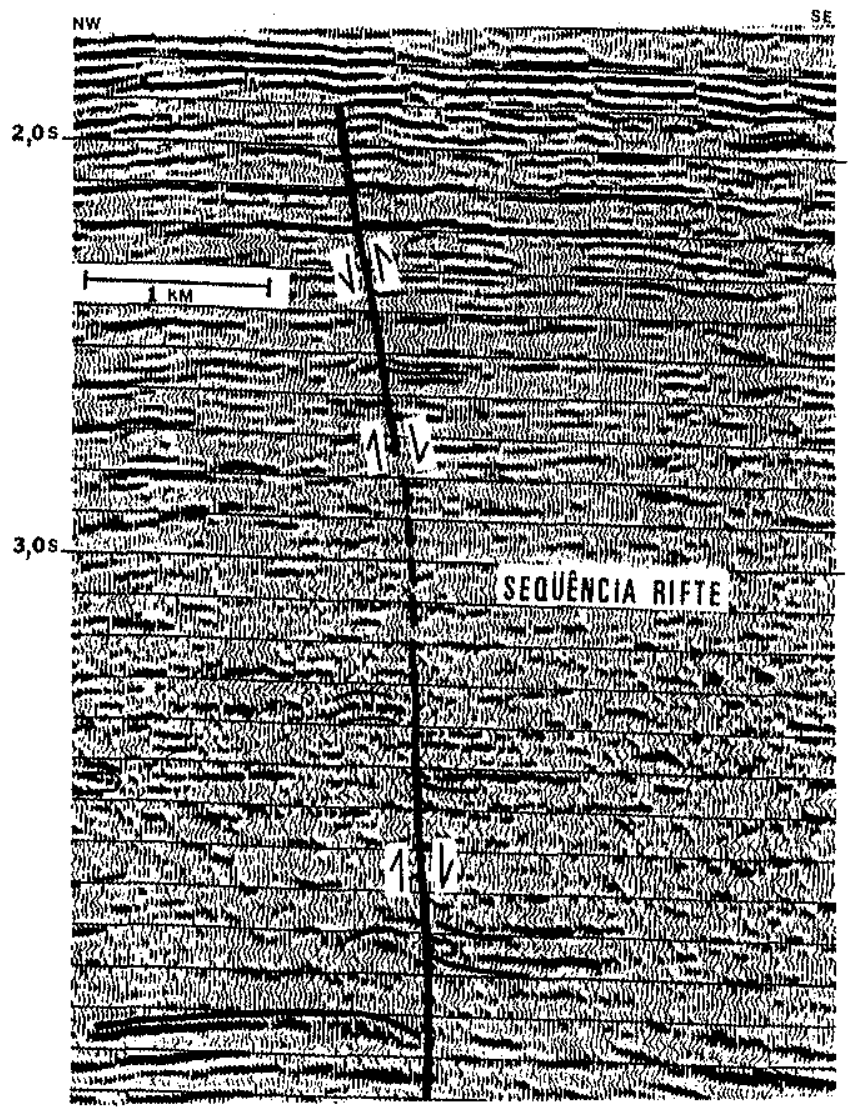

Figura 10 - Seção em tempo migrada mostrando outro exemplo de falha com reversão no rejeito aparente com a profundidade. Sistema Cretáceo da Bacia de Piaui-Camocim. Seção em tempo migrada

Poços perfurados em ambos os lados da falha poderão fornecer subsídios importantes para esses dois últimos critérios. Há casos, entretanto, em que as mudanças nas fácies sedimentares justapostas, ou em suas espessuras, não são tais que permitam sejam elas detectadas mediante seus atributos sísmicos. Nestes casos, os dados de poços são essen. ciais para se caracterizar a falha como transcorrente. A análise detalhada da evolução estratigráfica dos pacotes justapostos poderá indicar diferenças marcantes, tais como discordâncias de um dos lados da falha (tendência de bloco alto) correspondentes à deposição de fácies sedimentares típicas de blocos baixos (fanglomerados, folhelhos lacustres etc.), do outro lado. De uma maneira geral, correlações estratigráficas complexas através da falha constituem boas in. dicações de falhas transcorrentes (Fig. ID).

- Mudanças abruptas de elementos ou atitudes estruturais através da falha. Deslocamentos laterais de grande magnitude podem justapor áreas com diferentes evoluçōes tectônicas (diferentes deformações). Conseqüentemente, padrões estruturais diversos poderão ocorrer lado a lado. Por exemplo, um embasamento granítico (zona cega, em seção sísmica) poderá estar justaposto a um embasamento metassedi. mentar de um cinturão de dobramentos (refletores fortes, subparalelos e dobrados, em seção sísmica). Um pacote sedimentar não perturbado tectonicamente poderá ocorrer lado a lado com um pacote sedimentar altamente estruturado (oriundo de uma região previamente perturbada). Pequenos deslocamentos laterais podem justapor diferentes flancos das dobras en échelon. O resultado disto é uma abrupta mudança nos ângulos de mergulho dos estratos através da falha (D'Onfro \& Glagola 1983).

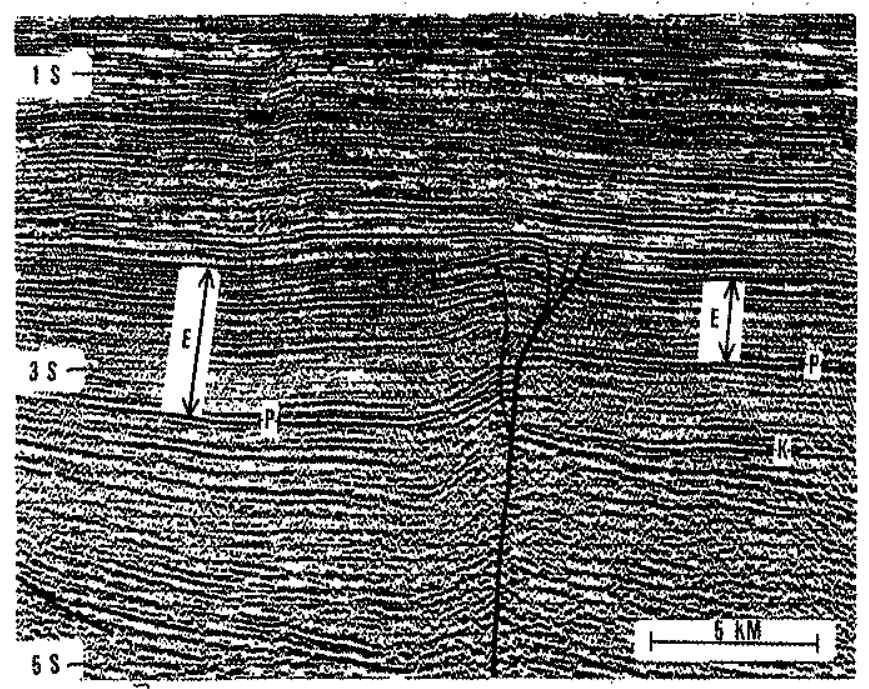

Figura 11 - Seção em tempo migrada mostrando falha com dobra de arrasto de falha normal abaixo do topo do Paleoceno (refletor $P$ ) e dobra de arrasto de falha reversa na seção do Eoceno (E). Tal falha comportou-se como normal do Cretáceo ao Eoceno (desde a fase rifte) e foi reativada como transcorrente dextral ao final do Eoceno, quando entäo esforços transpressionais originaram as dobras de arrasto re. versas nos sedimentos eocênicos. Observar as espessuras maiores dos pacotes do Eoceno e Paleoceno no bloco baixo da falha. $O$ topo do Cretáceo $(K)$ näo foi identificado no bloco baixo da falha, mas deve se situar abaixo dos 4 segundos. Bacia da Foz do Amazonas. Adaptado de Aguiar et al. (1986)

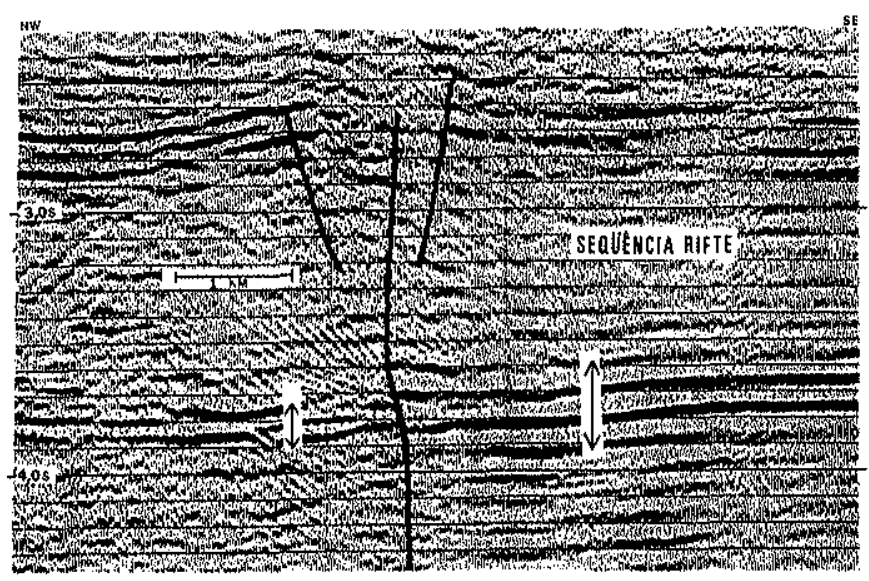

Figura 12 - Seção em tempo migrada mostrando uma falha subvertical com uma regiäo em cunha cega (sem refletores, provavelmente devido a intenso quebramento) sobrelevada na parte superior, e espessuras anomalamente diferentes da mesma fácies sismica (refletores fortes, subparalelos $e$ continuos, vide setas) lado a lado na parte inferior. Sistema Cretáceo da Bacia de PiauíCamocim 
De uma maneira geral, toda vez, que o geólogo ou geofísico constatar que as mudanças estratigráficas/estruturais são muito marcantes, ou abruptas, de um lado para outro de uma falha, a hipótese de transcorrência deverá ser investigada. Todas as linhas sísmicas que cortem a falha deverão ser analisadas com cuidado em busca dos critérios aqui discutidos.

Geometrias Complexas do Plano de Falha Por serem geralmente subverticais, as falhas transcorrentes aparecem, em mapa, como traços retilíneos, levemente sinuosos. Em seções verticais, entretanto, os traços dos planos de falhas transcorrentes podem apresentar geometrias muito complexas (vide os experimentos de Emmons 1968). Mudanças no sentido do mergulho, tendência à diminuição do ângulo de mergulho de baixo para cima, semicírculos e meia-taças são geometrias comuns de traços de falhas transcorrentes em seçōes sísmicas (Figs. 13 e 14).

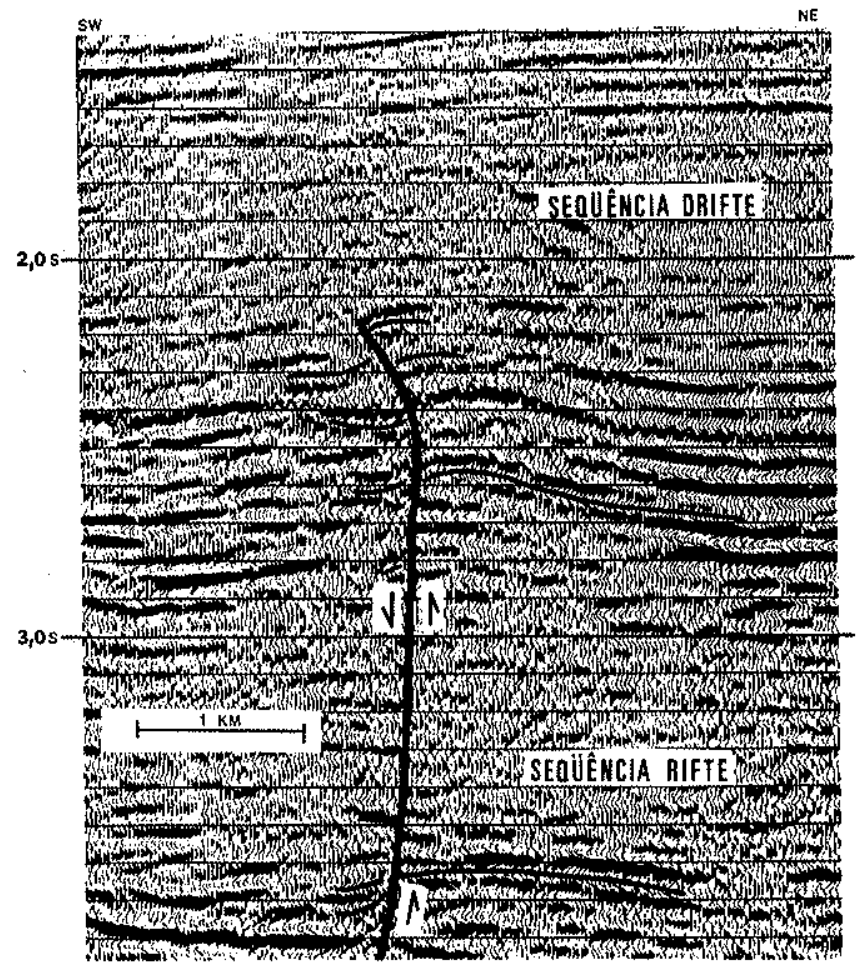

Figura 13 - Seção em tempo migrada mostrando mudança no sentido do mergulho de falha transcorrente. De $2,5 \mathrm{~s}$ para baixo, a falha é normal. De 2,5 s para cima, a falha é reversa. Sistema Cretáceo da Bacia de Piaui-Camocim

Torna-se necessária, às vezes, uma boa dose de coragem ao geofísico para interpretar tais geometrias. Ele sabe que certamente será alvo de críticas de colegas mais tradiciona* listas e menos atualizados acerca da evolução dos conhecimentos sobre tectônica transcorrente. Cabe aos geólogos documentarem e mapearem, em campo, tais geometrias não-convencionais. A Bacia do Paraná, por exemplo, tem-se mostrado uma generosa portadora de estruturas associadas a falhas transcorrentes (dados inéditos da Petrobrás). À medida que tal documentação for se avolumando, os geofísicos ficarão cada vez mais confiantes em interpretar, em seções sísmicas, aquilo que seus olhos vêem, seus corações sentem que é verdadeiro, mas suas mentes relutam em aceitar.

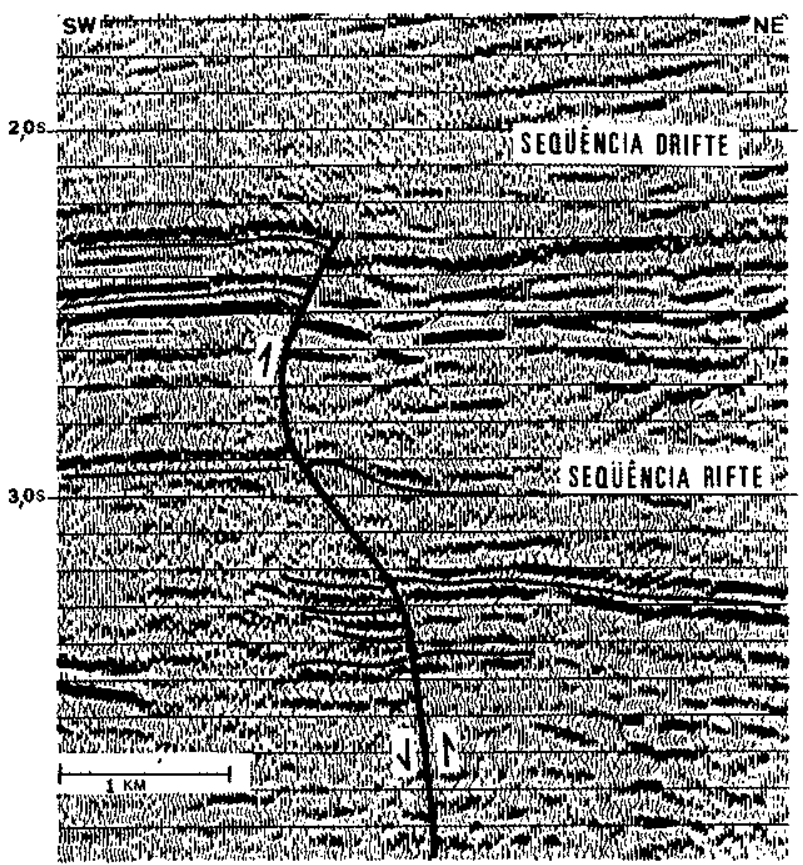

Figura 14 - Seção em tempo migrada mostrando geometria de meia-taça de uma falha transcorrente. Sistema Cretáceo da Bacia de Piaui-Camocim

CONCLUSÕES Nove critérios para reconhecimento de falhas transcorrentes em seções sísmicas foram apresentados e discutidos. São frutos da evolução dos conhecimentos acerca de tectônica transcorrente, grandemente acelerada nestes últimos 30 anos, e de um acúmulo gigantesco de dados sísmicos nos mais diversos tipos de bacia do mundo inteiro.

Tais critérios são: 1) estruturas-em flor (positivas ou negativas); 2) mudança no caráter da falha (de normal para reversa) ao longo de sua direção; 3 ) mudança do bloco alto, de um lado para outro, ao longo de sua direção; 4) mudanças gerais (de caráter e de bloco alto) ao longo de sua direção; 5) reversão do rejeito aparente da falha com a profundidade; 6) mudanças abruptas na espessura de fácies sísmicas ou intervalos estratigráficos através da falha; 7) mudanças abruptas de fácies sísmicas através da falha; 8) mudanças abruptas de estruturas e intensidade e/ou estilos de deformaçōes através da falha; e 9) geometrias complexas do plano de falha.

Torna-se muito importante frisas que, desses critérios, só as estruturas-em-flor podem ser usadas isoladamente como indicadores definitivos de transcorrência (desde que corretamente identificadas, Harding 1985). Os outros critérios devem ser usados coletivamente, isto é, deve-se ter a ocorrência de três ou quatro deles ao longo da direção de uma falha para que se possa ter certeza do caráter transcorrente dela.

A utilidade de tais critérios reside no fato de serem necessárias poucas seções sísmicas (três, às vezes apenas uma) cortando a falha com espaçamentos grandes ou pequenos, para se determinar a existência de tectonismo transcorrente em uma área de exploração. Tal reconhecimento torna a 
direção (orientação) de uma falha altamente favorável para a pesquisa de trapas estruturais diversas. Além disso, essas condições (poucas linhas sísmicas e largamente espaçadas) são as mais comumente encontradas durante os estágios iniciais de exploração em qualquer bacia sedimentar. O mapeamento de falhas e dobras en échelon (estruturas básicas de tectonismo transcorrente) requer um grande número de seções sísmicas regularmente espaçadas a pequenas distâncias, condições estas não tão facilmente encontradas.
Agradecimentos Expresso meus agradecimentos à Petrobrás, na pessoa do Superintendente-geral do Depex Milton Romeu Franke, pela autorização para publicar este trabalho. Agradeço também ao geofísico Luis Augusto M. Aguiar pelo acesso aos dados de seu recente trabalho (ainda inédito) na Foz do Amazonas.

\section{REFERENCIAS BIBLIOGRAFICAS}

AGUIAR, L.A.M.; JINNO, K.; MATOS NETO, J.B. - 1986 - Tectonismo transpressional na Foz do Amazonas. Rio de Janeiro, Petrobrás/Supex. 10p. (Rel. Int.).

BALLANCE, P.F. \& READING, H.G., ed. - 1980 - Sedimentation in oblique-slip mobile zones. Spec. Publ. Internat. Assoc. Sediment., n.0 4, $264 \mathrm{p}$.

BODENHAUSEN, J.W.A. \& OTT, W.F. - 1981 - Habitat of Rijswijk oil province, onshore, The Netherlands. In: ILLING, L.V. \& HOBSON, G.D. ed., Petroleum geology of the continental shelf of northwest Europe. London, Hayden \& Son, P. 301-309.

CROWELL, J.C. - 1974a - Sedimentation along the San Andreas Fault, California. In: DOTT, R.H. \& SHAVER, R.H. ed.,

if Modern and ancient geosynclinal sedimentation. Spec. Publ. SEPM, 19, p. 292-303.

CROWELL, J.C. - 1974b - Origin of Late Cenozoic basins in Southern California. In: DICKINSON, W.R. ed., Tectonics and sedimentation. Spec. Publ. SEPM, 22, p. 190-204.

CROWELL, J.C. - 1975 - The San Gabriel fault and Ridge Basin, Southern California. In: CROWELL, J.C. ed., San Andreas Fault in Southern California. Spec. Rep. California Div. Mines Geol., 118 , p. 208-233.

CROWELL, J.C. \& SYLVESTER, A.G. - 1979 - Tectonics of the junction between the San Andreas fault system and the Salton Trough - A guide-book. Department of Geological Sciences, University of California at Santa Barbara.

D'ONFRO, P. \& GLACOLA, P. - 1983 - Wrench fault, southeast Asia. In: BALLY, A.W. ed., Seismic expression of structural styles. AAPG Studies in Geology Series 15, v. 3, p. 4.2-9-4.2-12.

EMMONS, R.C. - 1968 - Strike-slip rupture patterns in sand models. Tectonophysics, 7:71-87.

FAGERLAND, N. - 1983 - Tectonic analysis of a Viking Graben border fault. AAPG Bull., 67(11):2125-2136.

GLENNIE, K.W. \& BOEGNER, P.L.E - 1981 - Sole pit inversion tectonics. In: ILLING, L.V. \& HOBSON, G.D. ed., Petroleum geology of the continental shelf of northwest Europe. London, Hayden Son, p. 110 120.

GRAHAM, S.A.; McCLOY, C.; HITZMAN, M.; WARD, R.; TURNER, R. - 1984 - Basin evolution during change from convergent to transform continental margin in central California. AAPG Bull., 68:(3):233-249.

HARDING, T.P. - 1973 - Newport-Iglewood trend, California An example of wrenching style of deformation. AAPG Bull., 57(1):97-116.

HARDING, T.P. - 1974 - Petroleum traps associated with wrench faults. AAPG Bull., 58(7):1290-1304.

HARDING, T.P. \& LOWELL, J.D. - 1979 - Structural styles, their plate-tectonic habitats, and hydrocarbon traps in petroleum provinces. AAPG Bull., 63(7):1016-1058.

HARDING, T.P. - $1983^{\circ}$ - Divergent wrench fault and negative flower structure, Andaman Sea. In: BALLY, A.W. ed., Seismic expression of structural styles. AAPG Studies in Geology Series 15, v. 3 , p. $4.2-1 \div 4.2-17$.
HARDING, T.P.; GREGORY, R.F.; STEPHENS, L.H. - $1983-$ Convergent wrench fault and positive flower structure, Ardmore Basin, Oklahoma. In: BALLY, A.W. ed., Seismic expression of structural styles. AAPG Studies in Geology Series $15, v .3, \mathrm{p} .4 .2 \times 13-4.2-17$.

HARDING, T.P. - 1985 - Seismic characteristics and identification of negative flower structures, positive flower structures, and positive structural inversion. AAPG Bull., 69(4):582-600.

HARLAND, W.B. - 1971 - Tectonic transpression in Caledonian Spitzbergen. Geolog. Mag., 108:27-42.

KINGMA, J.T. - 1958 - Piercment structures, unconformities and secondary basins in the eastern geosyncline, New Zealand. New Zealand J. Geol. Geophys., 1:269-274.

KINGSTON, D.R.; DISHROON, C.P.; WILLIAMS, P.A. - 1983 Global basin classification system. $A A P G$ Bull., 67(12):2175-2193.

LOWELL, J.D. - 1972 - Spitzbergen Tertiary orogenic belt and the Spitzbergen fracture zone: GSA Bull., 83:3091-3102.

MOODY, J.D. \& HILL, M.J. - 1956 - Wrench fault tectonics. GSA Bull., 67:1207-1246.

READING, H.G. - 1980 - Characteristics and recognition of strikeslip fault systems. In: BALLANCE, P.F. \& READING, H.G. ed., Sedimentation in oblique slip mobile zones. Spec. Publ. Internat. Assoc. Sediment., n. 04 , p. 7-26.

SYLVESTER, A.G. \& SMITH, R.R. - 1976 -, Tectonic transpression and basement-controlled deformation in San Andreas fault zone, Salton Trough, California. $A A P G$ Bull, 60(12):2081-2102.

TCHALENKO, J.S. - 1970 - Similarities between shear zones of different magnitudes. GSA Bull., $81: 1625-1640$.

WILCOX, R.E.; HARDING, T.P.; SEELY, D.R. - 1973 - Basic wrench tectonics. AAPG Bull., 57(1):74-96.

WILSON, J.T. - 1965 - A new class of faults and their bearing on continental drift. Nature, 207(4995):343-347.

ZALÁN, P.V. - 1984 - Tectonics and sedimentation of the PiauiCamocim sub-basin, Ceará Basin, offshore northeastern Brazil. Golden, Colorado. 133 p. (Ph. D. Thesis, Colorado School of Mines).

ZALÄN, P.V. \& WARME, J.E. - 1985 - Tectonics and sedimentation of the Piaut-Camocim sub-basin, Ceará Basin, offshore northeastern Brazil. Rio de Janeiro, Petrobrás/Cenpes. 71 p. (Cien.-Tec. Petróleo 17).

ZIEGLER, P.A. - 1981 - Evolution of sedimentary basins in northwest Europe. In: HOBSON, G.D. ed., Petroleum geology of the continental shelf of northwest Europe. London, Hayden \& Sons, p. 3-39.
MANUSCRITO

Recebido em 12 de maio de 1986 Revisão aceita em 17 de outubro de 1986 